ISSN: 2644-1217

\title{
Medical Procedure Guide
}

\author{
Uqbah Iqbal*, Ishak Sood, Yusoff K, Mazlam Zawawi, Shahdan Shahid, Abd Wahab Sufarlan and Zainudin Zain \\ School of History, Politics and Strategy, Faculty of Social Sciences and Humanities, Malaysia
}

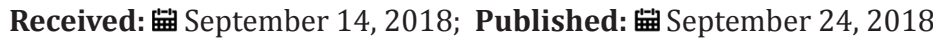

*Corresponding author: Uqbah Iqbal, School of History, Politics and Strategy, Faculty of Social Sciences and Humanities, UKM 43650, BangiSelangor, Malaysia

\section{Opinion}

This book provides a comprehensive guide to the procedures to be followed when performing various techniques commonly practiced in hospitals and clinics. All these procedures are expected to assist students and medical practitioners to make a diagnosis and determine a reasonable treatment. The authors hope that with this guidebook, students and medical practitioners will better understand and understand these procedures and be able to do so properly and effectively. The contents of this book can be said to cover a broad scope and how the writing is in such a way as to facilitate the instruction being practiced. The writing and content of this book is based on the experience of the author as a medical practitioner and instructor and based on what the author usually does at their institution, Universiti Kebangsaan Malaysia.

This book is started with a cardiovascular system. Each electrocardiography has a positive pole and a negative pole. In essence, these canals can be concentrated on any angle and in relation to the heart. According to the convention, there are 12 electrocardiographys, ie, I, II, III, aVR, aVL, aVF, and VI to V6, from the perspective of the respiratory system, pleural effusion often requires inhalation of pleural fluid and pleural biopsy to be performed for diagnosis purposes. In most cases, both procedures are best carried out at the same time. The indicator is for diagnosis purposes, in particular to ensure whether or not there is effusion, infection, malignancy, empiema or hemothorax, the second is for treatment purposes, for example to relieve the congestion, to remove pus or blood and occasionally inject antibiotic or anticancer drugs. From the point of gastroenterology, the nasogastric tube will be used. The indications are lavage gaster to detect some diseases, distributing adequate food for body needs, detecting and treating poisoning, emptying gaster to treat acute abdominal pain or before or during an emergency surgery is to be performed.
The equipment used is a large nasogastric tube so it is not easy to clog, but for the sake of nutrition it is preferable to use small size, lignocaine jelly, $50 \mathrm{ml}$ and litmus paper. The procedure is first, the patient is adequately informed about the procedure and the purpose. The second is the distance between the nose and the gaster measured first, usually between $40-50 \mathrm{~cm}$. Thirdly, there's no need for a sterile way but keep the situation clean. The fourth is insert a little Lignocaine jelly into the nose groove and apply it to the end of the tube. Fifth is to advise the patient to sit if possible, then insert the tube according to the nasal floor (rather than the direction of the nose), preferably a little bow head. The sixth is the patient being swallowed when the tube is inserted (if there is no danger, give a little water to swallow, the seventh is the suction of the gaster with the siring.) If it does not work, enter the air by swirling while listening to the sound of bubbles in the gastric epi with the stethoscope. the test of liquid is inhaled with litmus paper The ninth is, if you are still in doubt, take the abdomen x-ray to ensure the end of the tubing Tenth is to use normal water first if the tube is used to feed the food. This condition occurs, pull the tube out and try again. If the tube is left too long, this can cause ulcer and graft penetration.

From the renal system, the urethral stenosis is a procedure that is often performed and should not be considered mild and should be performed by trained staff. From the point of view of the hematological system, venous punctures are the most frequent and important procedures in medicine. It has a very wide indication and there is no absolute contraindication, but it should be exercised with caution especially if it is carried out against patients with coagulation or bleeding problems. The equipment used is cotton, $5 \%$ spirit solution, 2I G-type disposable needle, binder rubber, $10 \mathrm{ml}$ or $20 \mathrm{ml}$ and specimen bottle. 
(C) (i) This work is licensed under Creative Commons Attribution 4.0 License

To Submit Your Article Click Here: Submit Article

DOI: 10.32474/OAJCAM.2018.01.000102

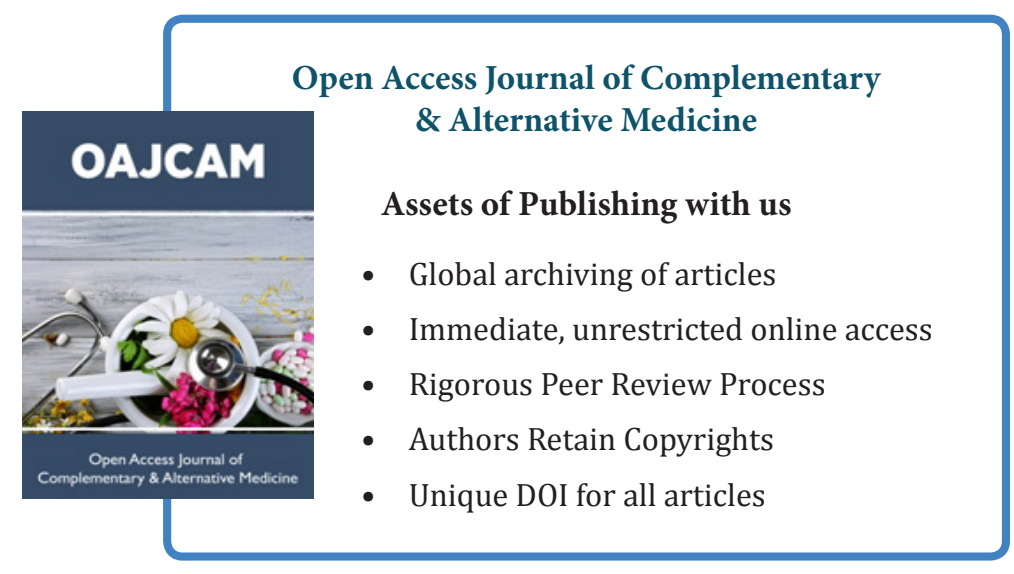

